\title{
Impact of COVID-19 pandemic on the health-related anxiety and behavioral changes among pregnant women - A cross-sectional study
}

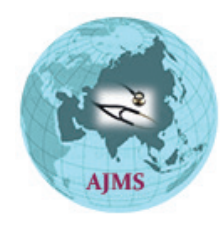

\author{
Ranita Roy Chowdhury ${ }^{1}$, Suvobrata Sarkar ${ }^{2}$, Manidip Pal ${ }^{3}$, Jayeeta Mukherjee ${ }^{4}$, \\ Gairik Bera ${ }^{5}$ \\ ${ }^{1}$ Associate Professor, ${ }^{2,4}$ Assistant Professor, ${ }^{3}$ Professor and Head, ${ }^{5}$ Post-Graduate Trainee, Department of Obstetrics and \\ Gynaecology, College of Medicine and JNM Hospital, W.B.U.H.S, Kalyani, Nadia, West Bengal, India
}

Background: The outbreak of COVID-19 has been the cause of agony for millions of people worldwide. Anxiety of losing near ones and stress of rearing children besides bearing the bulk of domestic tasks have led to certain behavioral changes in the pregnant women. Aims and Objectives: This study aims to assess anxiety, awareness, and behavioral changes among pregnant women during COVID-19 pandemic. Materials and Methods: A cross-sectional study was conducted in the Department of Obstetrics and Gynaecology, College of Medicine and J.N.M. Hospital, Kalyani, West Bengal, India, from May 1, 2020, to December 31, 2020. All antenatal patients after the second trimester visiting the OPD or maternity ward, satisfying inclusion criteria after formal consent, were considered for the study. Results: Out of a total of 139 patients, mostly primigravida, 122 (87.7\%) participants were of $18-33$ years age. Observations revealed that $24 \%$ more women were worried about their own health after the arrival of pandemic. The overall worry percentage for unborn baby (88\%), existing children (76\%), and older relatives (38\%) remained uniform throughout the study period. Staying at home, stocking of food, and medical equipment showed a downward trend toward the end of the study. Conclusion: The impact of the pandemic has been mammoth, taking a toll on the behavior and anxiety of the pregnant women, which when unnoticed may have a long-term effect on their mental health as well as family life. Physical and mental support from external and internal sources will pave the way to a healthier mental well-being of these antenatal mothers.

Key words: Self-worry; Health anxiety; Child support; Stock
Access this article online

\section{Website:}

http://nepjol.info/index.php/AJMS

DOI: $10.3126 /$ ajms.v12i11.38572

E-ISSN: 2091-0576

P-ISSN: 2467-9100

Copyright (c) 2021 Asian Journal of Medical Sciences

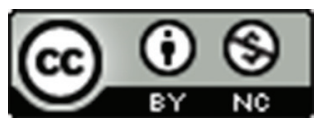

This work is licensed under a Creative Commons Attribution-NonCommercial 4.0 International License.

\section{INTRODUCTION}

The present emergency is due to the outbreak of COVID-19, a new, first identified in Wuhan, China, which rapidly spread across the borders, becoming a global public health threat. ${ }^{1}$ The current COVID-19 pandemic is considered as an example of a natural disaster in which more than 162 million people worldwide are suffering from it and more than 3 million people died. Correspondingly, India has second rank among the countries with the most coronavirus cases in the world, with 30,946,074 infected people and more than 411,408 deaths. $^{2}$
The prenatal period is often accompanied by maternal mental distress and behavioral changes associated with pregnancy itself. Pregnant women are often concerned about fetal health and the outcome of childbirth. Pregnancy is an immune compromised state, and biological adaptive changes during pregnancy could make women more vulnerable to viral respiratory infections, such as influenza, severe acute respiratory syndrome (SARS), and Middle East respiratory syndrome (MERS). ${ }^{3}$ There is very little information on pregnancy and its complications during coronavirus infection. However, according to previous epidemics of SARS and MERS, which were associated with several physical 
and psychological changes during pregnancy, ${ }^{4}$ pregnant women are more affected by the virus. Although, there is a paucity of documentation available regarding vertical transmission, assessment, and management of pregnant women infected with COVID-19 superimposed with rapid increase in number of COVID-19 cases certainly results in an increased level of stress and anxiety among pregnant women. ${ }^{3,5}$

Social distancing has resulted in inadequacy of social supports for many pregnant women as they are separated from their loved ones, whom they rely on for the support during this critical phase. While the social support helps pregnant women to increase their endurance, inconsistent social support is one of the significant risk factors for anxiety and depression among these women. ${ }^{6}$

The expectant women also face some special challenges due to the responsibility of caring for other children and family members. On the other hand, the need to receive regular care from maternity services increases the risk of exposure to infection with viruses in this population group. ${ }^{7}$

In normal times, it is likely that worldwide around $10 \%$ of pregnant women suffer from mental disorder, predominantly depression which is even higher $(16 \%)$ in developing countries. ${ }^{8}$ Notably, it was found that there is a relationship between pregnancy anxiety and insecurity in antenatal women which may be aggravated during COVID-19 pandemic when they may have limited access to mental health services. ${ }^{9}$ Furthermore, mental health is known to be an essential factor in maternal health and embryonic development. ${ }^{10}$ However, as yet, the association between fear and anxiety caused by a coronavirus and pregnancy experience has not been examined, and there is no study on this subject. Therefore, in this study, we sought to assess maternal fear and anxiety due to COVID-19, pregnancy experience, and mental health. The pandemic and its effect on the mental health of antenatal mothers are still under evaluation. The study proposes to assess its impact in this part of the state.

\section{Aims and Objectives}

This is a cross-sectional study which aims to assess anxiety, awareness, and behavioral changes among pregnant mothers during COVID-19 pandemic.

The objectives of the study were as follows:

1. To ascertain the trend of following preventive measures for COVID-19 (instructed by government).

2. To determine the behavioral changes among pregnant mothers.

\section{MATERIALS AND METHODS}

The study was conducted in the department of obstetrics and gynecology from May 1, 2020, to December 31, 2020. All antenatal patients in the second and third trimesters visiting the OPD and those admitted in the maternity ward, satisfying the inclusion and exclusion criteria after proper consent were recruited for the study. A formal institutional ethical clearance was undertaken before the initiation of the study.

\section{Inclusion criteria}

All antenatal patients in the second and third trimesters were included in the study.

\section{Exclusion criteria}

All pregnant with non-viable pregnancy, diagnosed fetal anomaly, previous non-viable pregnancy, suspected or confirmed COVID-19, and known psychiatric illnesses were excluded from the study.

\section{Description of procedure}

A questionnaire in local languages as well as in English was either handed over or asked to the patients and answers were noted in yes or no after their entry into the study. Outcome was assessed in terms of "Behavioral changes and Health Anxiety" in pregnant women.

\section{Flow diagram}

Eligible patients in OPD/maternity ward after consent.<smiles>[CH]</smiles>

Questionnaire following preventive measures for COVID-19 and behavioral changes.

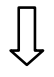

Data compiled and analyzed with appropriate statistical methods for the assessment of the patients.

\section{Statistical analysis}

The data thus collected after proper designing of the study were represented by basic statistical analysis. Microsoft Excel 2007 version 12, programming through Visual Basic for Application, was used for this purpose. The categorical variables (nominal) in the study were represented by contingency tables and bar graph.

\section{RESULTS}

In this study, 139 patients were questioned out of which 55 patients participated between May and July and 84 between August and December time period. There had 
been a remarkable behavioral change observed among these women during the 8 months study period. The results thus obtained were tabulated and graphically represented.

Age and gravida were the only demographic characteristics considered for the study. Most of the women were between 18 and 33 years $(87.76 \%)$ constituting mainly primigravida (76.97\%) who consented for the study. It was observed that $90 \%$ of the women were worried about their own health after the pandemic while it was $66 \%$ before the arrival of pandemic. The overall percentage of women who worried for unborn baby (88\%), existing children (76\%), and older relatives $(38 \%)$ remained uniform throughout the study period (Table 1). Table 1 also shows stocking trend had greatly reduced over the time. Between May-July and August-December, the stocking habit of food reduced from $78 \%$ to $48 \%$, hand sanitizer from $60 \%$ to $37 \%$, and medical equipment's including medicine, PPE, and mask from $16 \%$ to $5 \%$, respectively. In our study, no people have stored toilet paper or fuel at any point of time. We found women's requirements for additional child support reduced over the time, from $78 \%$ to $66 \%$. Surprisingly, people have shown more enthusiasm in shared care in later period (during April-June, 23\% of people were taking care of their baby by sharing whereas in July-December that increased to $61 \%$ ). It was observed that most of the women had similar source of information (Table 1). Television has the major contribution (96\%) in this category. Moreover, social media became an important information source in later period (69\%) compared to the first phase (46\%). Mobile applications (especially Aarogya Setu) and social media had similar impact in spreading information 65\% and $60 \%$, respectively, in our study period.

Figure 1 shows that people were uniformly worried about their family members during the entire study period. Only change was seen in "Self-worry after pandemic arrival" where we found that women seemed to be relatively less worried in later part of the study. All of them $(100 \%)$ during May-July were worried which reduced to $83 \%$ during August-December.

Figure 2 depicts a significant change in behavioral pattern. During May-July, about 33\% of people were either jobless or "working from home" whereas that reduced to $1 \%$ between August and December. There was a huge change in following "staying home" recommendation, during May-July, $73 \%$ of people were restricted to home while in August-December, it was only 6\%. (Both the above parameters were observed in case of male partners in our study).

\section{DISCUSSION}

The current COVID-19 pandemic is an example of a natural disaster in which millions of people have lost their lives and many more are suffering from it. Pregnancy is

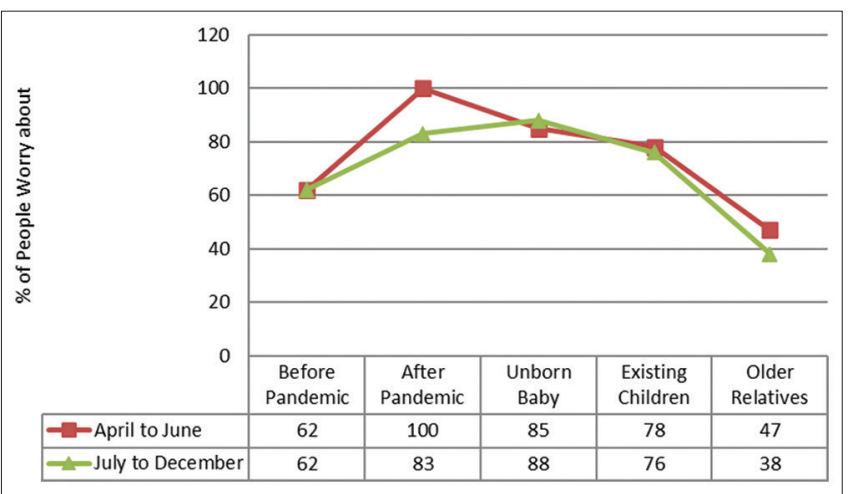

Figure 1: Percentage of people worry about themselves and their relatives

\begin{tabular}{|c|c|c|c|c|c|c|}
\hline & \multicolumn{2}{|c|}{ April-June } & \multicolumn{2}{|c|}{ July-December } & \multicolumn{2}{|c|}{ Overall } \\
\hline & Yes & No & Yes & No & Yes & No \\
\hline \multicolumn{7}{|l|}{ Stock } \\
\hline Hand sanitizer & $33(60 \%)$ & $22(40 \%)$ & $31(37 \%)$ & $53(63 \%)$ & $64(49 \%)$ & $75(51 \%)$ \\
\hline Toilet paper & $0(0 \%)$ & $55(100 \%)$ & $0(0 \%)$ & $84(100 \%)$ & $0(0 \%)$ & $139(100 \%)$ \\
\hline Fuel & $0(0 \%)$ & $55(100 \%)$ & $0(0 \%)$ & $84(100 \%)$ & $0(0 \%)$ & $139(100 \%)$ \\
\hline Medical equipment & $9(16 \%)$ & $46(84 \%)$ & $4(5 \%)$ & $80(95 \%)$ & $13(9 \%)$ & $126(91 \%)$ \\
\hline \multicolumn{7}{|l|}{ Child support } \\
\hline Additional support & $43(78 \%)$ & $12(22 \%)$ & $56(66 \%)$ & $28(34 \%)$ & $99(71 \%)$ & $40(29 \%)$ \\
\hline Stay home & $46(84 \%)$ & $9(16 \%)$ & $60(71 \%)$ & $24(29 \%)$ & $106(76 \%)$ & $33(24 \%)$ \\
\hline Shared care & $13(23 \%)$ & $42(77 \%)$ & $51(61 \%)$ & $33(39 \%)$ & $64(46 \%)$ & $75(54 \%)$ \\
\hline Grandparents & $36(65 \%)$ & $19(35 \%)$ & $51(61 \%)$ & $33(39 \%)$ & 87 (63\%) & $93(37 \%)$ \\
\hline \multicolumn{7}{|l|}{ Information center } \\
\hline TV & $51(92 \%)$ & $4(8 \%)$ & $82(98 \%)$ & $2(2 \%)$ & $133(96 \%)$ & $6(4 \%)$ \\
\hline Newspaper & $9(16 \%)$ & $46(84 \%)$ & $12(14 \%)$ & $72(86 \%)$ & $21(15 \%)$ & $118(85 \%)$ \\
\hline Mobile application & $33(60 \%)$ & $22(40 \%)$ & $57(68 \%)$ & $27(32 \%)$ & $90(65 \%)$ & $49(35 \%)$ \\
\hline Health service personal & $4(7 \%)$ & $51(93 \%)$ & $5(6 \%)$ & $79(94 \%)$ & $9(6 \%)$ & $130(94 \%)$ \\
\hline WHO website & $0(0 \%)$ & $55(100 \%)$ & $0(0 \%)$ & $84(100 \%)$ & $0(0 \%)$ & 139 (100\%) \\
\hline Social media & $25(46 \%)$ & $30(54 \%)$ & $58(69 \%)$ & $26(31 \%)$ & $83(60 \%)$ & $56(40 \%)$ \\
\hline
\end{tabular}




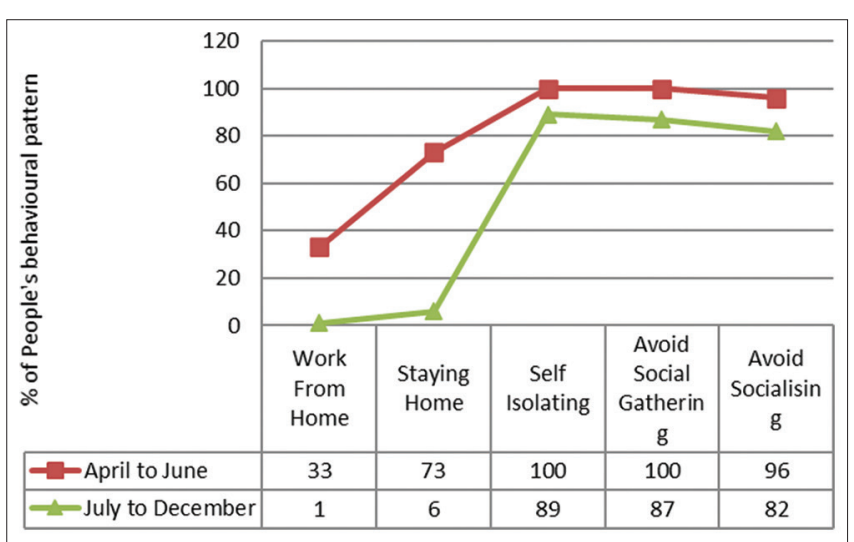

Figure 2: Percentage of people with changed behavioral pattern

a challenging phase of life. Many women suffer from anxiety, depression, and other mental disorders. They are supposed to take care of themselves as well as their family. They should go for routine antenatal check-ups for which they are required to visit the hospital or health-care centers which, in turn, increase the chances of contracting COVID. This pandemic has led to restriction of movements and regularly harped on the need to maintain social distancing.

This study was proposed to assess the impact of coronavirus pandemic on the behavior and mental health of pregnant women. The study participants had an average level of knowledge about the COVID-19 infection and about its prevention. The attitude and awareness of this form led to the acceptance to follow government guidelines on quarantine and social distancing. The worry levels identified in the study were high in the initial period. An important observation was that women started worrying about their own health after the advent of COVID-19 than they were before this pandemic. A similar study was published a year back based on a similar questionnaire in which the pregnant women had increased anxiety regarding their older relatives' health $(83.3 \%)$ compounded by concern about their existing children (66.7\%) and their unborn baby $(63.4 \%) .{ }^{11}$ In the current study, the overall percentage of women who worry for unborn baby $(88 \%)$, existing children (76\%), and older relatives $(38 \%)$ remained uniform throughout the study period.

Social distancing has led to loss of social supports for many antenatal women as they are separated from those who form the pillar of support during this crucial phase of life. While these social supports help pregnant women to recuperate, unreliable social support is one of the important contributory factors for depression among pregnant women. ${ }^{6}$ Besides, the link between the health-care system and pregnant was also cutoff which has correspondingly affected the maternal and child health. During the initial phase of the pandemic, a bias associated with hospitals due to COVID-19 has led to inadequate utilization of healthcare services. Most pregnant women were anxious with fear of acquiring infection in the hospital or in transit. ${ }^{5} \mathrm{~A}$ major change in behavior was also observed in our survey wherein self-isolation by the women, avoiding social gathering and avoiding socializing, was observed in around $90 \%$ of cases in each category. "Work from home" and "stay home" nomenclatures are meant for the male counterpart of the study participants as none of the women were working in this study. The government's sudden enforcement of the lockdown seemed to take a toll on migrant workers and daily wage earners who were left jobless. The vulnerable population was suffering from food insecurity. The stay home husbands were actually those working in informal economy. This was perhaps one of the probable reasons of increased domestic violence in this part of the world. A study published in April 2020 aptly depicted the Indian scenario in COVID last year. ${ }^{12}$

An Indian study showed that $72 \%$ of participants reported the need to use gloves, and sanitizers as majority were preoccupied with the thoughts of COVID-19. ${ }^{13}$ There was an increase in use of face masks by the general public worsening the global supply and leading to shortage of face masks, with prices soaring high. ${ }^{14,15}$ The tendency of stocking food reduced from $78 \%$ to $48 \%$, hand sanitizer from $60 \%$ to $37 \%$, and medical equipment's including medicine, PPE, and mask from $16 \%$ to $5 \%$, respectively, in the latter part of this study.

Widespread closure of schools due to sudden announcement of lockdown due to coronavirus infection made homestay mandatory for children. Thereby, child support in the form of caregiver became essential for both the working as well as non-working pregnant mothers. Since the families are likely to encounter a dearth of support from outsiders, such as from schools or childcare settings during the COVID-19 pandemic, it is essential that the aid they receive within the home alleviates their perceived stress and parenting. Given that the majority of participants were mothers; support for mothers in particular, should be considered as research indicates they bear the brunt of household and familial duties regardless of socioeconomic status. ${ }^{16,17}$

We found that people have fewer requirements for additional child support over the time, from $78 \%$ to $66 \%$. Surprisingly, people have shown more enthusiasm in shared care in later period which, in turn, implies that taking help outside became spontaneous once the women learned to cope up with the fear and insecurities related to the pandemic. With the dip in COVID curve toward the latter half of the study, people started socializing $(15 \%)$ as opposed to those $(2 \%)$ observed in the initial phase. Children were less likely to get affected with severe disease 
compared to adults in the first wave of COVID may be another important reason for opening up to shared care in the latter part of this study. Children accounted for a very small fraction of confirmed cases despite the sizable numbers of children tested as observed in studies published in the UK. ${ }^{18,19}$

Television has been the major source of information. Misconceptions may result in behaviors such as underestimation, fear, and taking inadequate measures to avoid infection which, in turn, are likely to cause further spread of epidemic.

Apart from television, social media gradually became an important information source in later period (69\%) compared to the time between April and June (46\%). Mobile applications (especially Aarogya Setu) almost had similar impact on spreading information (65\%) in the present study. Multiple information sources can increase public health awareness and the detection of inappropriate information during the COVID-19 pandemic. Videos on social media contribute to rumors among susceptible groups. ${ }^{20}$ Social media-related distress was reported to be $36.4 \%$ in one study. ${ }^{13}$

\section{Limitations of the study}

Since the study population is comparatively small compared to the patient load of this department; conclusion drawn from the study needs to be verified by a larger population based study.

\section{CONCLUSION}

A difference in the pattern of behavior was noted in patients in the initial phase of the COVID-19 pandemic as compared to those in the later part of the study. The pandemic has led to a worldwide health emergency, which, in turn, has affected lifestyle and mental health. Expectant, postpartum, miscarrying women, or those subjected to domestic violence are at high risk of developing mental health problems during the pandemic. Besides, parenting may be considerably more stressful during this time. Gender inequalities may be heightened, particularly for employed or single parents, as women overtly bear the bulk of domestic tasks, including childcare and eldercare. Improvement of social and family supports could lead to prevention, early detection, and appropriate management of behavioral issues promptly and effectively.

\section{REFERENCES}

1. Heymann DL. Data sharing and outbreaks: Best practice exemplified. Lancet. 2020;395(10223):469-470.

\section{https://doi.org/10.1016/s0140-6736(20)30184-7}

2. Available from: https://www.covid19.who.int/ info. [Last accessed on $2021 \mathrm{Jul}$ 15].

3. Luo $Y$ and Yin K. Management of pregnant women infected with COVID-19. Lancet Infect Dis. 2020;20(5):513-514. https://doi.org/10.1016/s1473-3099(20)30191-2

4. Schwartz DA and Graham AL. Potential maternal and infant outcomes from (Wuhan) coronavirus 2019-nCoV infecting pregnant women: Lessons from SARS, MERS, and other human coronavirus infections. Viruses. 2020;12(2):194.

https://doi.org/10.3390/v12020194

5. Fakari FR and Simbar M. Coronavirus pandemic and worries during pregnancy: A letter to editor. Arch Acad Emerg Med. 2020;8(1):e21.

6. Negron R, Martin A, Almog M, Balbierz A and Howell EA. Social support during the postpartum period: Mothers' views on needs, expectations, and mobilization of support. Matern Child Health J. 2013;17(4):616-623.

https://doi.org/10.1007/s10995-012-1037-4

7. Hussein J. COVID-19: What implications for sexual and reproductive health and rights globally? Sex Reprod Health Matters. 2020;28(1):1746065.

https://doi.org/10.1080/26410397.2020.1746065

8. Zeng LN, Chen LG, Yang CM, Zeng LP, Zhang LY and Peng TM. Comment: Mental health care for pregnant women in the COVID-19 outbreak is urgently needed. Women Birth. 2021;34(3):210-211.

https://doi.org/10.1016/j.wombi.2020.03.009

9. Topalidou A, Thomson G and Downe S. Covid-19 and maternal and infant health: Are we getting the balance right? A rapid scoping review. Practising Midwife. 2020;23(7):36-45. Available from: https://www.all4maternity.com/covid-19-and-maternaland-infant-health-are-we-getting-the-balance-right-a-rapidscoping-review. [Last accessed on 2021 Jul 14]. https://doi.org/10.1101/2020.03.30.20047969

10. Khatri GK, Tran TD and Fisher J. Prevalence and determinants of symptoms of antenatal common mental disorders among women who had recently experienced an earthquake: A systematic review. BMC Psychiatry. 2019;19:47. https://doi.org/10.1186/s12888-018-1986-2

11. Corbett GA, Milne SJ, Hehir MP, Lindow SW and O'connell MP. Health anxiety and behavioural changes of pregnant women during the COVID-19 pandemic. Eur. J. Obstet. Gynecol. Reprod. Biol. 2020;249:96-97.

https://doi.org/10.1016/j.ejogrb.2020.04.022

12. The Lancet. India under COVID-19 lockdown. Lancet. 2020;395(10233):1315.

https://doi.org/10.1016/s0140-6736(20)30938-7

13. Roy D, Tripathy S, Kar SK, Sharma N, Verma SK and Kaushal V. Study of knowledge, attitude, anxiety and perceived mental healthcare need in Indian population during COVID-19 pandemic. Asian J Psychiatr. 2020;51:102083. https://doi.org/10.1016/j.ajp.2020.102083

14. Feng S, Shen C, Xia N, Song W, Fan M and Cowling BJ. Rational use of face masks in the COVID-19 pandemic. Lancet Respir Med. 2020;8(5):434-436. https://doi.org/10.1016/s2213-2600(20)30134-x

15. Available from: https://www.who.int/news-room/detail/03-032020-shortage-of-personal-protective-equipment-endangeringhealth-workers-worldwide. [Last accessed on $2021 \mathrm{Jul}$ 13].

16. Bianchi SM, Sayer LC, Milkie MA and Robinson JP. Housework: Who did, does or will do it, and how much does it matter? Soc 
Forces. 2012;91(1):55-63.

https://doi.org/10.1093/sf/sos120

17. Brown SM, Doom JR, Lechuga-Peña S, Watamura SE and Koppels T. Stress and parenting during the global COVID-19 pandemic. Child Abuse Negl. 2020;110(Pt 2):104699.

https://doi.org/10.1016/j.chiabu.2020.104699

18. Bogiatzopoulou A, Mayberry $H$, Hawcutt DB, Whittaker $E$, Munro A, Roland D, et al. COVID-19 in children: What did we learn from the first wave? Paediatr Child Health (Oxford). 2020;30(12):438-443. https://doi.org/10.1016/j.paed.2021.01.001

19. Ladhani SN, Amin-Chowdhury Z, Davies HG, Aiano F, Hayden I, Lacy J, et al. COVID-19 in children: Analysis of the first pandemic peak in England. Arch Dis Child. 2020;105(12):1180-1185. https://doi.org/10.1136/archdischild-2020-320042

20. Zhou J, Ghose B, Wang R, Wu R, Li Z, Huang R, et al. Health perceptions and misconceptions regarding COVID-19 in China: Online survey study. J Med Internet Res. 2020;22(11):e21099. https://doi.org/10.2196/21099

Authors' Contributions:

RRC-Concept and design of the study, prepared the first draft of the manuscript; SS-Interpreted the results and reviewed the literature; MP-Concept, coordination, and revision of manuscript; JM-Statistical analysis and interpretation, revision of the manuscript; and GB-Data collection and preparation of manuscript.

\section{Work Attributed to}

College of Medicine and JNM Hospital, W.B.U.H.S, Kalyani, Nadia, West Bengal, India, Pin: 741235.

ORCID ID:

Dr. Ranita Roy Chowdhury- (iD https://orcid.org/0000-0003-4785-1438

Dr. Suvobrata Sarkar- (i) https://orcid.org/0000-0001-5758-034X

Dr. Jayeeta Mukherjee- (i) https://orcid.org/0000-0002-8818-0952

Dr. Gairik Bera- (i) https://orcid.org/0000-0001-8982-9998 